\title{
Toxic oil syndrome
}

INSERM

\section{Source}

INSERM. (1999). Orphanet: an online rare disease and orphan drug data base. Toxic oil

syndrome. ORPHA:227972

Toxic oil syndrome is a rare intoxication, due to consumption of a rapeseed oil denatured with aniline $2 \%$, characterized by generalized vascular lesions affecting all organs and vessels (including veins and arteries) and presenting with severe incapacitating myalgias, marked peripheral eosinophilia and pulmonary infiltrates. 